\title{
Study on the Applications of Planer Tool to the Decorative Line Patterns of Door Leaves in Taipei Story House
}

\author{
Ten-Li Chen ${ }^{1, \mathrm{a}}$; Ting-Chun Hsu ${ }^{2, \mathrm{~b}}$ \\ ${ }^{1}$ National Taipei University Of Technology, No.1, Sec. 3, Zhongxiao E. Rd., Taipei 10608 Taiwan (R.O.C) \\ ${ }^{2}$ (Corresponding Author) National Taipei University Of Technology, No.1, Sec. 3, Zhongxiao E. Rd., Taipei 10608 Taiwan (R.O.C) \\ a chent1@ntut.edu.tw, bhsu1030@gmail.com
}

\begin{abstract}
The wooden window frames of many traditional buildings in Taiwan have decorative line patterns carved with planer tool. However, these lines are easy to be damaged as the buildings age; and there are few studies on the technologies to conserve the lines. Therefore, this study explored the use of planer tool and regarded Taipei Story House as its sample. This study first carried out literature review and then field survey. It measured and recorded the size and patterns of components of wood doors of Taipei Story House. Then, it interviewed relevant carpenters proficient in planer tool to learn the principle of matching decorative line patterns with the styles and spatial characteristics of buildings.

The results show that, there are two types of door leaves in Taipei Story House, that is, sliding door and horizontal sliding door vertical hinged doors and horizontal sliding doors. The patterns of the doors include doors with square patterns, doors with irregular patterns, and straight line patterns. One doorleaf consists of four components, namely, door leaf, door frame, transom, and door sill. And planer tools for shape and planer tools for plane had been adopted to carve the lines. The preservation and recording of these traditional techniques of planer tool can serve as reference for future wood art learners for wood art culture preservation and repair.
\end{abstract}

Keywords: Building, Woodwork Learning, The Planer Tool

\section{Introduction}

Since ancient times, doors and windows play significant roles in traditional architecture, which not only present styles and materials, but also embed the value of exquisite craftsmanship and unique historical and cultural styles. The decorative line patterns (referred to as lines) on the wood components in traditional architecture were carved by traditional craftsmen with various types of planer tools. As technology advances, woodworking tools and wood art techniques are gradually being replaced by electric tools and mechanical equipment; and traditional wood culture is gradually forgotten. In view of this, it is of importance to carry wood art forward and record and preserve wood art reflected in architecture.

Liu (2015) pointed out that, the patterns of doors and windows in ancient Chinese architecture follow specific laws. Such patterns are for functional and decorative purposes. And they demonstrate unfailing charm thanks to exquisite craftsmanship. Moreover, the decorative lines of doors and windows reflect the elegance of traditional art. Such traditional culture shall be continued and inherited. Chou
(2016) analyzed contemporary wood art learners and identified their characteristics: Wood art learners are interested in wood art, and eager to obtain the sense of achievement and improve their competitiveness. Moreover, they want to learn professional knowledge in furniture design and traditional techniques. Finally, after learning, the part of their lives besides work, life, and creation is also changed. And they benefit from wood art to enhance their aesthetic taste and spiritual characteristic related to wood art.

By functions, Taiwan's traditional planer tools can be classified into three categories, that is, A) planer tools for shape, B) planer tools for plane, and C) planer tools for curved surface. Planer tools for shapes is used to carve lines and grooves; planer tools for plane is adopted to process planes; and planer tools for curved surface is employed to carve curved surfaces (Wu, 2016). The two categories of planer tools were mostly applied to the doors and windows of Taipei Story House. However, the way to use a planer tool varies depending on the user's operation habits, planning with left or right hands, push-pull planning, and the texture of wood. Su (2011) argued that, although they were deeply affected by the pull-planning method during the period of Japanese occupation, traditional Taiwanese planning still retained the push-planning method of the Han nationality and improved the handle to be detachable.

Taipei Story House, has a long history. It was originally built in 1913 and designed by Japanese and British. In 1998 , it was designated as a third-level monument and named as "Yuanshan Mansion" by Taipei City Government. In 2003, Mrs. Guo-ci Chen sponsored to establish "Taipei Story House". Since then, this monument has been transformed to a mini-museum introducing Taiwanese life and culture. It is a rare British Tudor-style building in Taiwan. The first floor was built with brick as the load-bearing walls. The entrance door is in Ionic style. The second floor is a halftimber structure, composed of curved, vertical, and horizontal wooden strips. The outer walls are decorated by lines in branch and twig patterns. It has a double-faced pitched roof, and a Gothic tower and chimney. The windows are tall and narrow. The window panes are in small square shape (Official website of Taipei Story House, 2017). This building is full of characteristics. Thanks to well preservation, it keeps its original appearance, making it suitable for mapping research. Thus, this study is designated to deeply probe into the types and usage of planer tool. It also conducted field survey to learn the status quo of planer tool, analyzed its inspiration to wood art design and creation nowadays, and intended to carry forward the wood art cultural industry and techniques of Taiwan. 


\section{Research Design}

This study aimed to explore the types of planer tool used to carve the line patterns of doors and windows. First, it collected and analyzed the literature on building and planer tool, carried out field survey to measure the components of wood door leaves of Taipei Story House, and record the data on different line patterns, so as to learn the types of planer tool.

\section{A. Research Method}

1. Literature review: It is a method which centers on a topic to collect relevant information like research reports, books, and magazines for summarization and analysis. This study collected the literature on door and window decoration and patterns of traditional buildings, and types and techniques of planer tool. Also, it studied the history of Taipei Story House.

2. Field survey. It means the onsite observation, measurement, shooting, and recording of an area, and the conversion of data after systematic summarization into useful knowledge. This study analyzed the patterns, sizes, styles, and corresponding techniques of planer tools of all the door leaves in Taipei Story House and used digital camera to record.

3. Interview of experts: Experts in culture and history or traditional craftsmen are interviewed to learn an idea or obtain a reliable answer. The interviewees of this study are traditional carpenters who described their experience orally. Past planning experience and planer tools were regarded as the main interview bases.

\section{B. Research Process}

1. Prerequisite knowledge: This study conducted preliminary literature and data collection on planer tool so as to learn the usage and functions of traditional planer tools and their corresponding parts and components of a building, and summarized the planer tools used to carve the lines of door leaves.

2. Field Survey: In order to understand the types of planer tools used for different components of door leaves, this study investigated the line patterns of Taipei Story House and measured the door leaves to collect data.

3. Induction and analysis: It then induced and analyzed the data measured. First, it encoded the types of planer tools and drew relevant pictures. Then, it classified the door leaves into different categories by style, number, and way to open so as to confirm their corresponding types of planer tool.

\section{Research Samples}

Taiwan's traditional planer tools vary in usage and functions. By functions, they can be classified into three categories, that is, planer tools for shape, planer tools for plane, and planer tools for curved surface. This study investigated the types of planer tool used to carve the lines patterns of door leaves of Taipei Story House. The names of the planer tools used include nine categories, that is, ChingHan-Di plane (P1), Gua-Bian plane (P2), Zhong-Bian plane (P3), Nei-Yuan plane (P4), Wai-Yuan plane (P5), Xie-Kou plane (P6), Zi-Ran-Mian-Qu plane (P7), He-Si-Jiao-Xian plane (P8), and Ping-Mian plane (P9). After mapping, investigation, and comparison, this study summarized the names and pictures of planer tools and the corresponding lines they can carve into Table 1 .

TABLE 1

Planer tools and their corresponding lines

\begin{tabular}{|c|c|c|c|c|}
\hline Code & Type & $\begin{array}{c}\text { Name of } \\
\text { Planer Tool }\end{array}$ & Picture & Line \\
\hline P1 & $\begin{array}{l}\text { planer tools } \\
\text { for shape }\end{array}$ & $\begin{array}{l}\text { Ching-Han-Di } \\
\text { plane }\end{array}$ & & \\
\hline P2 & $\begin{array}{l}\text { planer tools } \\
\text { for shape }\end{array}$ & $\begin{array}{l}\text { Gua-Bian } \\
\text { plane }\end{array}$ & & \\
\hline $\mathrm{P} 3$ & $\begin{array}{l}\text { planer tools } \\
\text { for shape }\end{array}$ & $\begin{array}{l}\text { Zhong-Bian } \\
\text { plane }\end{array}$ & & \\
\hline P4 & $\begin{array}{l}\text { planer tools } \\
\text { for shape }\end{array}$ & $\begin{array}{l}\text { Nei-Yuan } \\
\text { plane }\end{array}$ & & \\
\hline P5 & $\begin{array}{l}\text { planer tools } \\
\text { for shape }\end{array}$ & $\begin{array}{l}\text { Wai-Yuan } \\
\text { plane }\end{array}$ & & \\
\hline P6 & $\begin{array}{l}\text { planer tools } \\
\text { for plane }\end{array}$ & Xie-Kou plane & & \\
\hline P7 & $\begin{array}{l}\text { planer tools } \\
\text { for shape }\end{array}$ & $\begin{array}{l}\text { Zi-Ran-Mian- } \\
\text { Qu plane }\end{array}$ & & \\
\hline P8 & $\begin{array}{l}\text { planer tools } \\
\text { for shape }\end{array}$ & $\begin{array}{l}\text { He-Si-Jiao- } \\
\text { Xian plane }\end{array}$ & & \\
\hline P9 & $\begin{array}{l}\text { planer tools } \\
\text { for plane }\end{array}$ & $\begin{array}{l}\text { Ping-Mian } \\
\text { plane }\end{array}$ & & $={ }^{\dagger}$ \\
\hline
\end{tabular}

\section{Research Analysis}

This study regarded Taipei Story House as its sample and conducted field survey. First, it analyzed the types and spatial location of door leaves. Then, it recorded the way to open and number of door leaves. Finally, it compared the lines of the four types of door leaves with their corresponding planer tools and concluded the following results.

TABLE 2

Number and spatial location of door leaves

\begin{tabular}{|c|c|c|c|c|}
\hline Style & Function & way to ope & & Space names \\
\hline \multirow{3}{*}{$\begin{array}{l}\text { square } \\
\text { patterns }\end{array}$} & \multirow[t]{2}{*}{$\begin{array}{c}\text { vertical } \\
\text { hinged } \\
\text { door }\end{array}$} & $\begin{array}{l}\text { single- } \\
\text { door }\end{array}$ & 5 & $\begin{array}{l}\text { 1st floor dining room } \\
\text { storage room } \\
\text { 2st floor bedrooms } \\
\text { Japanese room }\end{array}$ \\
\hline & & $\begin{array}{l}\text { double- } \\
\text { door }\end{array}$ & 3 & $\begin{array}{l}\text { 1st floor Hallway } \\
\text { Living room } 、 \text { Porch }\end{array}$ \\
\hline & $\begin{array}{c}\text { horizontal } \\
\text { sliding } \\
\text { doors }\end{array}$ & $\begin{array}{l}\text { double- } \\
\text { door }\end{array}$ & 1 & $\begin{array}{l}\text { living room to the dining } \\
\text { room on the } 1 \text { st floor }\end{array}$ \\
\hline \multirow{2}{*}{$\begin{array}{l}\text { irregular } \\
\text { patterns }\end{array}$} & \multirow{2}{*}{$\begin{array}{l}\text { vertical } \\
\text { hinged } \\
\text { door }\end{array}$} & $\begin{array}{l}\text { single- } \\
\text { door }\end{array}$ & 1 & $\begin{array}{l}\text { 2st floor stairwell to the } \\
\text { Sitting Area }\end{array}$ \\
\hline & & $\begin{array}{c}\text { double- } \\
\text { door }\end{array}$ & 1 & $\begin{array}{l}2 \text { st floor Sitting Area to } \\
\text { the front balcony }\end{array}$ \\
\hline $\begin{array}{l}\text { straight } \\
\text { lines }\end{array}$ & $\begin{array}{c}\text { vertical } \\
\text { hinged } \\
\text { door }\end{array}$ & $\begin{array}{l}\text { double- } \\
\text { door }\end{array}$ & 6 & $\begin{array}{l}\text { 1st floor reception } \\
\text { room - Dining room 、 } \\
2 \text { st floor Bedroom 、 } \\
\text { Japanese room } \\
\text { Study 、 stairwell }\end{array}$ \\
\hline
\end{tabular}




\section{A. Floor plan and space analysis of Taipei Story House}

This study investigated the spatial location of the four types of door leaves, as shown in Table 2 and Figure 1. First, vertical hinged door with square patterns. Single-doors are located in the dining room and storage room on the first floor, and bedrooms and Japanese-style rooms on the second floor. Double-doors are located at the entrance, living room, and staircase leading to rear balcony on the first floor. Second, horizontal sliding doors with square patterns. It only has double-doors. They are located in the main channel from the living room to the dining room. Third, vertical hinged door with square patterns. Single-doors are located at the staircase on the second floor leading to the small hall. Double-doors are used to connect the small hall to the front balcony. Lastly, vertical hinged doors with straight lines are located at the reception room and the dining room on the first floor and bedrooms, Japanese-style rooms, and staircase on the second floor.

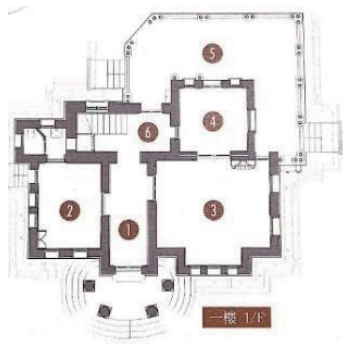

(a) Floor plan of the 1st floor

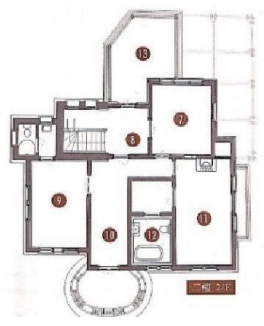

(b) Floor plan of the 2nd floor

\begin{tabular}{cc}
\hline Number & space names \\
\hline 1 & Hallway \\
\hline 2 & $\begin{array}{c}\text { Reception } \\
\text { Room }\end{array}$ \\
\hline 3 & $\begin{array}{c}\text { Living } \\
\text { Room }\end{array}$ \\
\hline 4 & $\begin{array}{c}\text { Dining } \\
\text { Room }\end{array}$ \\
\hline 5 & Porch \\
\hline 6 & $\begin{array}{c}\text { First floor } \\
\text { stairwell }\end{array}$ \\
\hline 7 & $\begin{array}{c}\text { Japanese } \\
\text { Room }\end{array}$ \\
\hline 8 & $\begin{array}{c}\text { Second floor } \\
\text { stairwell }\end{array}$ \\
\hline 9 & Study \\
\hline 10 & Sitting Area \\
\hline 11 & Bedroom \\
\hline 12 & Bathroom \\
\hline 13 & $\begin{array}{c}\text { Bonsai } \\
\text { Corner }\end{array}$ \\
\hline &
\end{tabular}

(c) Plane and space names
Figure 1. Space plan

(Source of the material : Taipei Story House - For the Taipei International Flora Exposition)

\section{B. Analysis of the space types of door leaves of Taipei Story House}

The space surrounded by door leaf design of Taipei Story House can be classified into public and private space. The door leaves can be classified into four types, as shown in Figure 2, namely, vertical hinged doors with square patterns (Figure 2- a), horizontal sliding doors with square patterns (Figure 2- b), vertical hinged doors with irregular patterns (Figure 2-c), vertical hinged doors with straight lines (Figure 2-d). Based on the four types, the types of door leaf can be classified by function (vertical hinged doors and horizontal sliding doors), style (square pattern, irregular pattern, and straight line patterns), and way to open (single-door and double-door), as shown in Table 2 and described as follows:

1. By function, there are mainly two types, that is, vertical hinged doors and horizontal sliding doors. There are 16 vertical hinged doors, used in private and public space. There is only one horizontal sliding door. It is used in the public space of the main channel from the living room to the dining room on the 1 st floor, to increase penetration and expansibility of the space.

2. By style, the doors can be classified into square patterns, irregular patterns, and straight line patterns. The number of doors with square patterns is the most $(9$ doors), followed by straight line patterns (6 doors), and irregular patterns ( 2 doors) in order, mainly distributed in public space like the entrance, the living room, the dining room, and the rear balcony. Thus, we can see that the design of doors of Taipei Story House prefer orderly line patterns. And square patterns are the main design style.

3. By way to open, there are double-door and single-door. Most of the doors are double-doors (11), while there are 6 single-door. They are mainly distributed in public space like entrance, the living room, the dining room, and the reception room. In terms of the spatial transition design of Taipei Story House, double-doors are preferred to be used in public space for convenience in entry and exit without barrier.

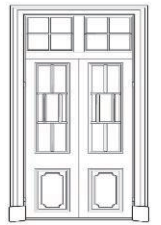

(a) vertical hinged door with square patterns

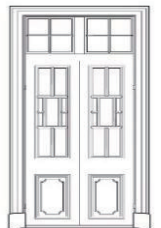

(C) vertical hinged doors with irregular patterns

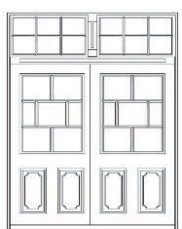

(b) horizontal sliding doors with square patterns

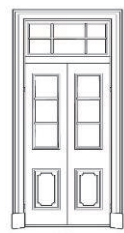

(d) vertical hinged doors with straight line patterns
Figure 2. Classification of door leaves

\section{Analysis of planer tools for door leaves of Taipei Story House}

After investigation and comparison, this study finds that, there are four types of door leaves, as shown in Table 3 and described as follows:

1. The lines of vertical hinged door with square patterns were mainly carved by He-Si-Jiao-Xian plane (P8). Their door frames were mainly carved by Ching-HanDi plane (P1) and Gua-Bian plane (P2). The surrounding lines were carved by six types of planer tools including Zhong-Bian plane (P3), Nei-Yuan plane (P4), Wai-Yuan plane (P5), Xie-Kou plane (P6), and so on. The transoms on doors were carved by Zi-RanMian-Qu plane (P7).

2. The lines of horizontal sliding doors with square patterns were mainly carved by He-Si-Jiao-Xian plane (P8). Their door frames were mainly carved by Ching- 
Han-Di plane (P1) and Gua-Bian plane (P2). The surrounding lines were carved by six types of planer tools including Zhong-Bian plane (P3), Nei-Yuan plane (P4), Wai-Yuan plane (P5), Xie-Kou plane (P6), and so on. The transoms on doors were carved by Zi-Ran-Mian-Qu plane (P7). And the door sills were carved by Zhong-Bian plane (P3) and Ping-Mian plane (P9).

3. The lines of vertical hinged doors with irregular patterns were mainly carved by He-Si-Jiao-Xian plane (P8). Their door frames were mainly carved by Ching-Han-Di plane (P1) and Gua-Bian plane (P2). The surrounding lines were carved by six types of planer tools including Zhong-Bian plane (P3), Nei-Yuan plane (P4), Wai-Yuan plane (P5), Xie-Kou plane (P6), and so on. The transoms on doors were carved by Zi-Ran-Mian-Qu plane (P7).

4. The lines of vertical hinged doors with straight line patterns were mainly carved by He-Si-Jiao-Xian plane (P8). Their door frames were mainly carved by ChingHan-Di plane (P1) and Gua-Bian plane (P2). The surrounding lines were carved by six types of planer tools including Zhong-Bian plane (P3), Nei-Yuan plane (P4), Wai-Yuan plane (P5), Xie-Kou plane (P6), and so on. The transoms on doors were carved by Zi-Ran-Mian-Qu plane (P7).

TABLE 3

Comparison between components of door leaves and planer tools

\begin{tabular}{|c|c|c|c|c|c|}
\hline Parts & Fun & $\begin{array}{l}\text { vertical } \\
\text { hinged } \\
\text { door with } \\
\text { square } \\
\text { patterns }\end{array}$ & $\begin{array}{l}\text { horizontal } \\
\text { sliding } \\
\text { doors with } \\
\text { square } \\
\text { patterns }\end{array}$ & $\begin{array}{l}\text { vertical } \\
\text { hinged } \\
\text { doors with } \\
\text { irregular } \\
\text { patterns }\end{array}$ & $\begin{array}{l}\text { vertical } \\
\text { hinged } \\
\text { doors with } \\
\text { straight } \\
\text { line } \\
\text { patterns }\end{array}$ \\
\hline \multirow{2}{*}{$\begin{array}{l}\text { door } \\
\text { leaves }\end{array}$} & Planer tool & P8 & P8 & P8 & P8 \\
\hline & Lines & & & & \\
\hline \multirow[b]{2}{*}{$\begin{array}{c}\text { door } \\
\text { frames }\end{array}$} & Planer tool & $\begin{array}{l}\text { P1,P2,P3, } \\
\text { P4,P5,P6 }\end{array}$ & $\begin{array}{l}\text { P1,P2,P3, } \\
\text { P4,P5,P6 }\end{array}$ & $\begin{array}{r}\text { P1,P2,P3, } \\
\text { P4,P5,P6 }\end{array}$ & $\begin{array}{r}\text { P1,P2,P3, } \\
\text { P4,P5,P6 }\end{array}$ \\
\hline & Lines & 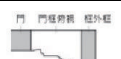 & 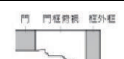 & 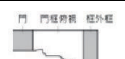 & \begin{tabular}{l|l}
19 \\
1
\end{tabular} \\
\hline \multirow{2}{*}{$\begin{array}{l}\text { transo } \\
\mathrm{ms}\end{array}$} & Planer tool & P7 & P7 & P7 & P7 \\
\hline & Lines & & & & 4 \\
\hline \multirow{2}{*}{$\begin{array}{l}\text { door } \\
\text { sills }\end{array}$} & Planer tool & - & P3, P9 & - & - \\
\hline & Lines & - & 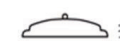 & - & - \\
\hline
\end{tabular}

\section{Conclusion}

This study considered the door leaves of Taipei Story House as its samples, conducted field survey on planer tools, interviewed experts on the applications of planer tools to the lines of door leaves, and measured the line patterns carved by each type of planer tool. The results demonstrate that, there are a total of 17 door leaves, classified into four categories, that is, vertical hinged door with square patterns, horizontal sliding doors with square patterns, vertical hinged doors with irregular patterns, and vertical hinged doors with straight line patterns. There are 11 double-doors and 6 single-doors. The number of vertical hinged double-doors with straight line patterns (6) is the most, followed by vertical hinged single- doors with square patterns (5). Hence, double-doors is mainly adopted in this building.

Besides, through investigation and comparison, this study probed into the relationship between types and components of door leaves. It finds that, among the four types of doors (vertical hinged door with square patterns, horizontal sliding doors with square patterns, vertical hinged doors with irregular patterns, and vertical hinged doors with straight line patterns), the lines of door frames were carved by the most number of planer tools (6), where Ching-Han-Di plane (P1) and Gua-Bian plane (P2) were mainly used. In terms of surrounding lines, Zhong-Bian plane (P3), Nei-Yuan plane (P4), Wai-Yuan plane (P5), and Xie-Kou plane (P6) were used. Additionally, only horizontal sliding door with square patterns has a door sill. As such door can be opened by pulling horizontally, the lines were mainly carved by Zhong-Bian plane (P3) and Ping-Mian plane (P9). Lastly, among the four types of door leaves, all the lines on door leaves were mainly carved by He-Si-Jiao-Xian plane (P8). And the lines on transoms were mainly carved by Zi-Ran-Mian-Qu plane (P7). Therefore, the investigation and comparison conducted by this study can serve as reference for future wood art learners for wood art culture preservation and inheritance.

\section{Acknowledgement}

We are grateful to the Executive Yuan and Ministry of Science and Technology for funding under project No. MOST 106-2221-E-027-079.

\section{References}

[1] Chang-Ju Wu, Inheritance and Innovation of Craft -A Case Study of Traditional Wood Working Plane, National Taipei University of Technology Master Program of Innovation and Design, 2016.

[2] Chun-Ming Huang, Taipei City Art Museum Artist Association Center (Yuanshan Beizhuang) Report on commissioned Planning for investigation and reuse of repairs and maintenance, The Taipei Municipal Government entrusts the Central Yuan University Architecture Research Institute Project, 1999.

[3] Han-Li Liu, Rules of formal composition of decorative patterns of Chinese traditional doors and windows, Art education research, 2015, pp.24-26.

[4] Jing-Ping Shiau, A Study of the Adaptive Reuse of Heritage and Museum Leisure-Visitor Experience at Taipei Story House(Master thesis), Department of Tourism College of Managements Providence University,2006.

[5] Kuo-Tzu Chen, Taipei Story House - For the Taipei International Flora Exposition, Taipei Story House Planning, 2010, Taipei-Old Story Store.

[6] Nien-Ping Yin - Ssu-Yi Chao, Appreciation of the Art of window Decoration in Ancient Chinese Architecture, Architectural knowledge, Issue 2, 2007, pp. 52-56.

[7] Wen-Ching Su, Study of Traditional Taiwanese Woodworking Planes and their Transition, Cultural Heritage Conservation Journal 17, 2011, pp. 61-72.

[8] Ya-Kuan Cho \& Ting-Chun Hsu, A Study on Learning Motivation in Woodwork Heritage, International Journal of Cultural and Creative Industries (IJCCI), 4(1), 2016, pp. 3847. 